\title{
Could dental school teaching clinics provide better care than regular private practices?
}

\begin{abstract}
Summary
Dental school clinics (DSC) consist of unlicensed dental students delivering care under the supervision of licensed dental professionals. Care delivery is slow due to inexperience of the provider and the series of supervisory checks that are necessary. Cost of care to the patient is less. To date, there has been no evaluation of the benefits of receiving care in a DSC beyond reduced fees. Research has shown the value of teaching hospitals in medicine, and the purpose of this article was to evaluate the total sum of benefits (the value proposition) of receiving dental care in a DSC.
\end{abstract}

\section{1 | INTRODUCTION}

In the dental profession, we are privileged that many patients choose to seek care in DSC, which facilitate the training of future dentists and the sustenance of our profession. DSC are unique environments. Unlicensed, novice providers deliver care to patients under the supervision of licensed dental professionals. Utilization of novice providers is in conflict with financial sustainability goals of the academic institution. A DSC can have 30,40 , or more dental chairs, and this environment is quite different to a private dental practice setting. In dentistry, patients value their relationship with their primary care provider, and the constant transition of dental school providers (as they graduate) is another challenge to building a sustainable business model. Although there is a growth in the number of group practices, ${ }^{1}$ only $34.7 \%$ of UK practice operate in practices with four or more dentists. ${ }^{2}$ In the USA, approximately $70 \%$ of dental offices are sole proprietors. ${ }^{3}$ This is a different environment compared to the structure of DSC.

\section{2 | OBJECTIVE}

A review of dental academic institution websites across the world suggests that, collectively, we do poorly at marketing the unique product DSC offer to their patients. The definition of a value proposition of a product is the sum benefits a consumer will gain from purchase of the goods or services being marketed; it is the reason why a consumer should purchase a product. Some dental academic institutions focus on reduced cost as the only value proposition of care in a DSC. No dental academic institution website in the UK or USA uses a marketing strategy that highlights the true value proposition their
DSC offers customers. The objective of this article was to highlight the numerous benefits of receiving care in a dental school; the value proposition of a DSC.

\section{3 | SHARED GOALS}

Dental schools are highly-structured organizations with mission statements and guiding principles. Time magazine has reported on the importance of mission statements, and describes how they can form a framework for self-evaluation and help employees focus their efforts toward company goals. ${ }^{4}$ Most private dental practices are small entities that do not have a mission statement that is explicitly stated; this creates the risk of acting in conflict with your mission and values. For example, the goals of the dental profession are to optimize the oral health of the population at large. However, some activities of the profession might seem in conflict with this; for instance, an Office of Fair Trading investigation revealed that dentists have "deliberately misled" 500000 patients to pay private practice fees when they were eligible for National Health Services coverage in England. ${ }^{5}$ As a result of such conflicts globally, dentists have been criticized for being corrupt and money hungry, rather than interested in the oral health of the population. $^{6}$

\section{4 | HIERARCHY OF ACCOUNTABILITY}

Clinical operations at dental schools are coordinated by deans of clinical affairs. These deans often have a broad range of administrative support staff and report to the dean of the school. The school's dean, in turn, is held accountable by the board of the school, the university provost, and president. This large hierarchy of accountability means that patient care is always considered, patient outcomes are regularly reviewed, and patient satisfaction is constantly evaluated by various individuals and committees.

In contrast to this relatively high level of accountability in DSC, a private practice dentist graduates from dental school and is never subject to any further checks or accountability for the rest of their careers. Although severe breaches of standards can start a cascade of events, including legal action, and intervention by the Boards of Registration in Dentistry and Dental Associations, a mediocre dentist with no severe breaches faces no barriers in continuing their 
career. Literature reveals that the simple existence of a hierarchy of accountability (regardless of how effective it is) can result in better performance in operations, including patient care, known as the Hawthorne effect. ${ }^{7}$ If this monitoring system is effective, it can have an exponential effect on quality in DSC.

\section{5 | QUALITY}

The Commission on Dental Accreditation (CODA) accredits US dental schools. Standard 5 addresses patient care services in dental schools, and its intent is to promote patient-centered, evidencebased care. ${ }^{8}$ These goals result in the formation of quality assurance and quality improvement committees that routinely evaluate patient satisfaction, clinical outcomes, and error rates, and monitor a dashboard of critical measures. This results in robust, quality programs, where error rates are proactively studied and remake rates are monitored for negative trends. Commonly, no such monitoring system exists in smaller private practices.

Moreover, DSC require student providers' work to be checked by a licensed dentist at regular intervals. These regular evaluations serve as checkpoints, which have been shown to improve care in surgical procedures by preventing error and reducing distraction..$^{9-11}$ Hospital research has even demonstrated a reduction in mortality rate with the use of checklists that serve as checkpoints. ${ }^{12}$ The University of Michigan DSC use an electronic system to request faculty evaluation and feedback. Evaluation of this data (Institutional Review Board [IRB] approval from University of Michigan Medical School Committee on Human Research, no. HUM 00131029) demonstrates that between October 2015 and April 2017 there were 29974 unique patient visits and 131248 requests for faculty checks. This means that each patient visit had 4.38 faculty checkpoints on average.

In private practice, the dentist is fully licensed and not subject to any formal checks. They rely on self-assessment; however, research has proven that self-assessment is very poor. ${ }^{13}$ In fact, research has shown that those who are weak at a given task are also poor at selfassessment of that task, ${ }^{13}$ which creates the risk of being "unskilled and unaware". ${ }^{14}$ It is true that protection exists in terms of reporting of providers suffering from substance abuse and legal frameworks for frank incompetence. However, mediocre and substandard care that does not result in legal intervention or other critical incidents cannot be flagged in the current system where dentists are their own evaluator. It can be argued that the structure of constant evaluation and quality review has potential to facilitate superior care in a teaching practice.

\section{6 | PATIENT OUTCOMES}

Teaching hospitals have been shown to have higher quality, safety, and better patient outcomes in many areas compared to nonteaching hospitals. ${ }^{15,16}$ Hospitals are certainly different to DSC; however, consider the similarities. For example, the University of Michigan School of Dentistry (a medium-sized dental school) had close to 200000 outpatient visits last year. As the population ages and lives longer with chronic disease, DSC are regularly called upon to deliver complex care to complex patients. In medicine, there are many examples of a shift from inpatient procedures to outpatient care, ${ }^{17,18}$ which suggests that the differences between teaching hospitals and DSC are reducing.

Research in medicine has demonstrated that high-volume hospitals perform better in patient outcomes. These hospital learn from errors and near errors, and perfect the process to optimize outcomes. Bhatia et al. found that patients who receive care for heart failure in hospitals with lower admission rates for heart failure have higher rates of re-admission and emergency room visits. ${ }^{19}$ However, in an interview, Bhatia went on to say: "Larger community and academic hospitals are more likely to have better access to specialty physicians, diagnostic testing, and bed availability". ${ }^{20}$ These advantages are not unlike the advantages of a DSC. In the DSC at the University of Michigan School of Dentistry between 1 April 2016 and 30 April 30 2017, there were 333 complete lower dentures fabricated (IRB approval from University of Michigan Medical School Committee on Human Research, no. HUM 00131160). While complete lower dentures can be very challenging to construct, large academic centers are able to learn from a high volume of cases and use continuous improvement to provide high-quality care. Even if a small private practice delivered one complete lower denture every single business day of the year, it would fall short of the volumes reached in the DSC of University of Michigan School of Dentistry (UMSOD).

Meguid et al. conducted a study on close to 50000 patients undergoing lung resection as a result of lung cancer, and found mortality rates to be lower at teaching hospitals. ${ }^{21}$ The investigators concluded that disseminating the processes of care in these teaching hospitals to other hospitals "may improve quality of care for lung cancer patients".

Laucis et al. studied knee and hip arthroplasty and found that each successively higher volume hospital had lower complication rates. $^{22}$ Shahian et al. studied how mortality for acute myocardial infarction, heart failure, and pneumonia varied across teaching hospitals and non-teaching hospitals. They found that, for each condition, teaching hospitals provided a $10 \%$ relative reduction in the adjusted odds of mortality for patients admitted to teaching hospitals, and this was regardless of the teaching intensity. ${ }^{23}$ Therefore, even the presence of a small amount of teaching improved outcomes at the hospital.

There is no study in dental medicine examining the impact of receiving care in a high-volume DSC versus a small private practice. A challenge in dentistry is that clinicians tend to use experience, rather than guidelines and evidence, to make clinical decisions. ${ }^{24}$ It works "in my hands" is a common mantra touted by many in our profession. In academic dental institutions, we are charged to teach our students evidence based dentistry and ensure that they learn how to distinguish good and bad evidence. 


\section{7 | PATIENT SATISFACTION}

One might presume that smaller private practices consider and manage patient satisfaction at superior levels. However, it is worth recognizing that few dentists in private practice actually measure patient satisfaction. ${ }^{25}$ However, without acquiring and synthesizing feedback, it is impossible to improve the experience of the customer. ${ }^{26}$ DSC have robust processes for measuring patient satisfaction. At UMSOD, three types of surveys are administered every year for a total of approximately 4000 surveys. Every patient who completes a treatment plan has the opportunity to complete a patient satisfaction survey. UMSOD also sends 200 surveys to patients who have chosen to discontinue care, and 750 point-of-service (POS) surveys are given to individuals who have just completed an appointment in the DSC. In our last administration of the POS survey, we had 179 responses out of 250 surveys (71.6\% response rate), and we found that $97.5 \%$ said they had a good understanding of their treatment plan (IRB approval from University of Michigan Medical School Committee on Human Research, no. HUM 00131160); however, the percentage was lower for new patients, which means we need to improve our education of new patients.

Moreover, CODA site visitors will review if findings from these surveys affect change at the DSC. Therefore, patients will have their voices heard, and one can be assured of constant improvement based on patient feedback at a DSC. No such process to ensure patient satisfaction is gathered and affects change is in existence in private practice.

\section{ACCESS TO CARE}

Dental schools can be huge organizations with hundreds of care providers and dental chairs. Access to care is extremely broad; although your own provider might not be able to help you, any DSC will have a myriad of providers who are capable of providing emergency care on any given day. Smaller practices cannot offer this level of service to its customers. Many DSC are also moving to offer regular appointments outside business hours. Moreover, DSC have a tight support network for after-hours emergencies. For example, at University of Michigan School of Dentistry, general practice residents are on call after hours and are supported by the division of hospital dentistry. Through the hospital, there is also access to oral surgeons and the emergency room doctors.

Shahian et al. found that major teaching hospitals are more likely to offer care to minorities and patients who need to be transferred from other hospitals for advanced care. ${ }^{27}$ Both are essential to an equitable and high-quality regional health-care system. In fact, a study in dental medicine has shown that few dental students intend to treat complex patients with special needs unless they had this experience in the protective and supportive environment of their dental school. ${ }^{28}$

Large teaching hospitals more often provide care to underserved populations. In fact, according to the Association of American
Medical Colleges, teaching hospitals provide a "disproportionate amount to care to the country's medically underserved". ${ }^{29}$ As a dental equivalent, consider the example of Massachusetts (which is one of the few states that makes insurance distribution publically available), where approximately only 1400 dentists accept Medicaid insurance out of the 6301 professionally-active dentists. ${ }^{30,31}$ This is only $22 \%$ of all active dentists. At UMSOD, only $32.9 \%$ of patients have private insurance: $22.4 \%$ have Medicaid, $9.5 \%$ have Affordable Care Act (ACA) plans, and $28.8 \%$ are uninsured (IRB approval from University of Michigan Medical School Committee on Human Research, no. HUM 00131160). It should be noted that the ACA in the USA mandated that dental insurance must be offered, but did not mandate that it should be accepted, thus many remain without dental insurance in the USA.

\section{9 | RESEARCH}

Dental schools are the center for research and innovation in dental medicine. Universities are primary sites for scientific discovery and clinical trials, and piloting new technology. Research has shown that hospitals participating in clinical trials have better overall outcomes. ${ }^{32}$ The Majumdar et al ${ }^{32}$ concluded that hospitals participating in clinical trials had lower mortality rates (not just for the condition in the clinical trial) and provide better care. The highly-structured environment of DSC is more suited for implementing research protocols and could produce better outcomes, because structure and reduced variability have been shown to reduce error rates and complications in hospitals. ${ }^{33,34}$

Additionally, dental schools tend to utilize new technology sooner (through research grants and expanded buying power) than smaller practices, and might be able to offer cutting edge standards of care sooner. ${ }^{15}$

\section{0 | MULTIPERSPECTIVE DECISION- MAKING}

Many faculty will complain about how slow decision-making and implementation in an academic institution can be in comparison with a small private practice. Moreover, faculty who remain connected to private practices might lament on how they make decisions with little conflict in their practice compared to academic institutions. However, literature has shown that multiple diverse opinions lead to more conflict and ensure better decision outcomes. ${ }^{35}$ Dentist in smaller private practices are the chief executive officer, chief operations officer, and chief financial officer. As such, her/his power is all encompassing, and employees are not usually empowered to provide conflicting opinions. Literature has described how powerful Chief Executive Officer can obliterate dissension, ${ }^{34}$ and the problem is that multiple perspectives are not considered and final decisions might not assess all the important factors. Many private dental offices might run like this and utilize weak decision-making processes. 
This is a strength of a DSC; that multiple opinions from individuals with various backgrounds (socioeconomic, academic, racial, and ethnic) are available for every important decision.

Moreover, within the DSC, a student might acquire several consultations (including specialists) in order to make a treatment decision; these consults are usually at no additional fee to the patient. For example, when the general dentist faculty wants a prosthodontic, periodontic, or endodontic consultation, they can ask a colleague, and usually do not charge the patient an additional fee. This adds value in two ways. First, more than one opinion is sought, which strengthens the final decision; and second, an expert opinion can be gained without additional fee to the patient. Such partnership in care is rarely available to the patient in the private practice model, even less so without additional fee.

\section{1 | CONCLUSION}

Academic institutions have greater resources than small private offices and are able to provide administrative support to clinic operations. For instance, DSC have administrators to review quality data, quality assurance committees to synthesize that information, and quality improvement groups to implement change when needed. DSC also have a hierarchy of accountability, better access for underserved individuals, formal checkpoints to reduce error, and multiple perspectives considered for all important decisions. The value proposition of DSC is much broader than simply inexpensive care. Academic dental centers should market their product as a comparable service to teaching hospitals, which are highly regarded for better outcomes in medicine.

\section{ORCID}

Romesh P. Nalliah iD http://orcid.org/0000-0002-6287-0656

\author{
Romesh P. Nalliah \\ Director of Clinical Education, \\ School of Dentistry, University of Michigan, \\ Ann Arbor, MI, USA
}

\section{REFERENCES}

1. General Dental Council in the UK. Changes to dental provision in the UK and the implications for the General Dental Council. A Policy Horizon Scanning Report. General Dental Council of UK:London, England; 2012.

2. British Dental Association. www.bda.org/dentists/policy-campaigns/research/workforce-finance/gp/Documents/challenges_to_ becoming_a_practice_owner___full_report.pdf. Accessed July 12, 16

3. American Dental Association. www.google.com/ u rl ? s a $=\mathrm{t} \& \mathrm{rct}=\mathrm{j} \& \mathrm{q}=\&$ e s r c $=\mathrm{s} \& \mathrm{~s}$ ou rce $=\mathrm{web} \& \mathrm{c}-$ $\mathrm{d}=3 \&$ ved $=0$ ah UKEwiYg 6 qh $9 \mathrm{rbNAhVIMFIKHR-}$ quA7sQFgguMAI\&url=http\%3A\%2F\%2Fwww. ada. org\%2F \%2Fmedia\%2FADA\%2FScience\%2520and\%2520Research\%2FHPI\%2FFiles\%2FHPIData_SDPC_2013.
ashx\&usg=AFQjCNEs6R_3hXjunpYm89K8n5McmWYsYQ\&sig2 = Lku7A16JaBgolHHLe7iN7w\&cad=rja. Accessed April 25, 2016

4. Time Magazine. http://business.time.com/2013/01/24/why-youneed-a-mission-statement/. Accessed June 20, 2016

5. The Telegraph newspaper. www.telegraph.co.uk/news/health/ news/9295340/Dentists-forcing-500000-NHS-patients-to-payprivately-report.html. Accessed June 20, 2016

6. Public Broadcasting Service. www.pbs.org/wgbh/frontline/film/ dollars-and-dentists/. Accessed June 12, 2016

7. Harvard Business School. www.library.hbs.edu/hc/hawthorne/09. html\#nine. Accessed May 16, 2016

8. American Dental Association. www.ada.org/ /media/CODA/ Files/2016_predoc.pdf?la=en. Accessed May 12, 2016

9. Arriaga $A F$, Bader AM, Wong JM, et al. Simulation-based trial of surgical-crisis checklists. N Engl J Med. 2013;368:246-253.

10. Enchev Y. Checklists in neurosurgery to decrease preventable medical errors: a review. Balkan Med J. 2015;32:337-346.

11. Ragusa PS, Bitterman A, Auerbach B, Healy WA 3rd. Effectiveness of surgical safety checklists in improving patient safety. Orthopedics. 2016;39:e307-e310.

12. Bock M, Fanolla A, Segur-Cabanac I, et al. A comparative effectiveness analysis of the implementation of surgical safety checklists in a tertiary care hospital. JAMA Surg. 2016;151:639-646.

13. Kruger J, Dunning D. Unskilled and unaware of it: how difficulties in recognizing one's own incompetence lead to inflated selfassessments. J Pers Soc Psychol. 1999;77:1121-1134.

14. Ehrlinger J, Johnson K, Banner M, Dunning D, Kruger J. Why the unskilled are unaware: further explorations of (Absent) selfinsight among the incompetent. Organ Behav Hum Decis Process. 2008;105:98-121.

15. Shahian DM, Nordberg P, Meyer GS, et al. Contemporary performance of U.S. teaching and nonteaching hospitals. Acad Med. 2012;87:701-708.

16. Pisu M, Wang D, Martin MY, Baltrus P, Levine RS. Presence of medical schools may contribute to reducing breast cancer mortality and disparities. J Health Care Poor Underserved. 2010;21:961-976.

17. Kamat AS, Parker A. Optimising neurosurgical outpatient care: a paradigm shift? J Prim Health Care. 2015;7:198-203.

18. Beans BE. Experts foresee a major shift from inpatient to ambulatory care. P T. 2016;41:231-237.

19. Bhatia RS, Austin PC, Stukel TA, et al. Outcomes in patients with heart failure treated in hospitals with varying admission rates: population-based cohort study. BMJ Qual Saf. 2014;23:981-988. https://doi.org/10.1136/bmjqs-2014-002816. Epub 2014 Jul 30.

20. Institute for Clinical Evaluative Sciences. www.ices.on.ca/ Newsroom/News-Releases/2014/Heart-failure-patients-havebetter-outcomes-when-treated-at-larger-community. Accessed May 15, 2016

21. Meguid RA, Brooke BS, Chang DC, Sherwood JT, Brock MV, Yang SC. Are surgical outcomes for lung cancer resections improved at teaching hospitals? Ann Thorac Surg. 2008;85:1015-1024; discussion 1024-5. doi: 10.1016/j.athoracsur.2007.09.046.

22. Laucis NC, Chowdhury M, Dasgupta A, Bhattacharyya T. Trend toward high-volume hospitals and the influence on complications in knee and hip arthroplasty. J Bone Joint Surg Am. 2016;98:707-712.

23. Shahian DM, Liu X, Meyer GS, Torchiana DF, Normand SL. Hospital teaching intensity and mortality for acute myocardial infarction, heart failure, and pneumonia. Med Care. 2014;52:38-46.

24. Nalliah RP. Clinical decision making - choosing between intuition, experience and scientific evidence. Br Dent J. 2016;221:752-754.

25. Dentistry IQ magazine. www.dentistryiq.com/articles/2010/04/ the-importance-of.html. Accessed May 29, 2016

26. Kennedy MM. What kind of feedback are you soliciting? Physician Exec. 1997;23:56-58. 
27. Shahian DM, Liu X, Meyer GS, Normand SL. Comparing teaching versus nonteaching hospitals: the association of patient characteristics with teaching intensity for three common medical conditions. Acad Med 2014;89:94-106.

28. Vainio L, Krause M, Inglehart MR. Patients with special needs: dental students' educational experiences, attitudes, and behavior. J Dent Educ. 2011;75:13-22.

29. Moy E, Valente E Jr, Levin RJ, Griner PF. Academic medical centers and the care of underserved populations. Acad Med. 1996;71:1370-1377.

30. Massachusetts Dental Society. MassHealth member participation rates. www.massdental.org/masshealth.aspx?id=2106. Accessed June 12, 2016

31. Kaiser Family Foundation. http://kff.org/other/state-indicator/total-dentists/. Accessed June 20, 2016

32. Majumdar SR, Roe MT, Peterson ED, Chen AY, Gibler WB, Armstrong PW. Better outcomes for patients treated at hospitals that participate in clinical trials. Arch Intern Med 2008;168:657-662.
33. Anderson M, Fitzgerald M, Martin K, et al. A procedural check list for pleural decompression and intercostal catheter insertion for adult major trauma. Injury. 2015;46:42-44.

34. Crosby E. Review article: the role of practice guidelines and evidence-based medicine in perioperative patient safety. Can J Anaesth. 2013;60:143-151. https://doi.org/10.1007/s12630-0129855-9. Epub 2012 Dec 5.

35. Eisenhardt KM, Kahwajy JL, Bourgeois LJ (III). How top management teams disagree. California Management Review 1997;39:42-62, NO. 2 Winter 1997

How to cite this article: Nalliah RP. Could dental school teaching clinics provide better care than regular private practices?. J Invest Clin Dent. 2019;10:e12329. https://doi. org/10.1111/jicd.12329 